\title{
Atividade antifúngica e cinética de morte microbiana de extratos obtidos de Streptomyces spp. isolados de solos paraibanos
}

\author{
Thompson Lopes de Oliveira, ${ }^{*}$, Edeltrudes de Oliveira Lima, ${ }^{2}$ Ivone Antonia de Souza, ${ }^{3}$ \\ Luis Conrado Z. Cornejo ${ }^{4}$
}

\author{
${ }^{1}$ Programa de Pós-graduação em Ciências Farmacêuticas, Universidade Federal de Pernambuco, \\ Av. Arthur de Sá s/n, Cidade Universitária, 50740-521 Recife-PE, Brasil \\ ${ }^{2}$ Departamento de Ciências Farmacêuticas, Universidade Federal da Paraíba, Av. Castelo Branco s/n, \\ Cidade Universitária, 58051-900 João Pessoa-PB, Brasil \\ ${ }^{3}$ Departamento de Antibióticos, Universidade Federal de Pernambuco, \\ 50740-521 Recife-PE, Brasil \\ ${ }^{4}$ Laboratório de Microbiologia, Facultad de Medicina, Universidad de Chile. \\ Av. Independência 1027, Santiago, Chile.
}

\begin{abstract}
RESUMO: Foram coletadas sessenta e oito amostras em diferentes solos paraibanos, com o isolamento de quarenta e nove cepas de Streptomyces spp. Após triagem antimicrobiana, por meio da técnica de difusão em meio sólido com blocos de agar, foram preparados os extratos dos microrganismos produtores de metabólitos bioativos, respectivamente cepas SP1 e SP3, e em seguida avaliados quanto a atividade antifúngica frente a espécies de fungos filamentosos de origem clínica e ATCC. O antagonismo foi determinado através dos ensaios de difusão com discos em meio sólido, microdiluição e cinética de morte microbiana. Os halos de inibição obtidos a partir dos extratos Sp-1 e Sp-3 apresentaram efeito antagônico com valores superiores aos halos de inibição promovidos pela droga controle, frequentemente utilizada na terapêutica antifúngica. Os resultados das concentrações inibitórias mínimas na microdiluição foram expressivos com valores fungicidas variando entre $10 \mathrm{mg}$ e $0,078125 \mathrm{mg}$. Na cinética de morte microbiana, as atividades dos extratos $\mathrm{Sp}-1$ e Sp-3 resultaram em dados estatisticamente significativos frente às cepas testes.
\end{abstract}

Unitermos: Streptomyces, extratos, atividade antifúngica, cinética.

\begin{abstract}
Antifungal activity and kinetics of microbial death of extracts obtained from Streptomyces spp. isolated from paraibano soils". Sixty eight samples were collected in different soils of Paraiba, with the isolation of forty nine strains of Streptomyces spp. After screening antimicrobial followed the method of diffusion in solid medium with agar block, the extracts were prepared from microorganism producers of bioactive metabolites, respectively strains SP1 and SP3, and then evaluated for antifungal activity against strains of filamentous fungi of clinical origin and ATCC. The antagonism was determined through testing of diffusion disc in solid medium, microdilution and kinetics of microbial death. The inhibition zones obtained from extracts of Sp-1 and Sp-3 showed antagonistic effect with values greater than the halos of inhibition promoted by the drug control, often used in antifungal therapy. The results of minimum inhibitory concentrations in microdilution were significant with fungicide values ranging between $10 \mathrm{mg}$ and $0.078125 \mathrm{mg}$. In the kinetics of microbial death, the activities of the extracts Sp-1 and Sp-3 resulted in statistically significant data front of strains tested.
\end{abstract}

Keywords: Streptomyces, extract, antifungic activity, kinectics.

\section{INTRODUÇÃO}

O uso indiscriminado e prolongado de drogas antimicrobianas sintéticas tem levado à seleção de microrganismos patogênicos cada vez mais resistentes, com perfis de multiresistência. Este problema é intensificado em países como o Brasil, onde a população tem por hábito a automedicação, utilizando de maneira indevida os antibióticos, em dosagens e posologia (Tresoldi et al., 2000). Em consideração à crescente importância clínica, laboratorial e terapêutica dispensada às infecções fúngicas e bacterianas, inúmeras pesquisas vem sendo desenvolvidas no sentido de obter novos fármacos naturais ou sintéticos, que sejam menos tóxicos e apresentem atividade contra 
cepas de microrganismos resistentes (Lima et al., 1975).

Dessa forma, a pesquisa com organismos produtores de metabólitos ativos com efeito antagônico contra cepas de fungos e bactérias está sendo cada vez mais difundida em todo o mundo. Cerca de $84 \%$ dos antibióticos de origem natural encontrados são produzidos por microrganismos do solo em especial os Streptomyces spp. com resultados extremamente eficazes (Sanches-Marroquin, 1958). Os Streptomyces, dentre os Actinomycetes, lideram a produção de antibióticos e moléculas farmacologicamente ativas, enquadradas em uma diversidade de classes, como: aminoglicosídio, macrolídio, ansamacrolídio, beta-lactâmico, peptídio, glicopeptídio, antraciclina, tetraciclina, nucleosídio, polieno e quinona (Garcia-Quintana, 1997).

Desta forma, a utilização da ecologia na prospecção de microrganismos de interesse biotecnológico isolados de solos e de plantas medicinais, tornou-se mais frequente e vem mostrando a descoberta de novos metabólitos bioativos (Strobel \& Daisy, 2003; Wiyakrutta et al., 2004; Li et al., 2005).

Portanto, julgou-se oportuno a realização desta pesquisa com objetivo de avaliar a capacidade de antagonismo através da produção de metabólitos bioativos pelas cepas nativas de Streptomyces spp isoladas de solo paraibano e cepas fúngicas de origem clínica e ATCC.

\section{MATERIAL E MÉTODOS}

\section{Coleta de amostras e isolamento de colônias de} Streptomyces spp

Foram coletadas sessenta e oito amostras de solo do leito dos principais rios que formam as bacias hidrográficas no Estado da Paraíba, distribuídos nas seguintes mesorregiões: Litoral Paraibano, Agreste Paraibano, Borborema e Sertão Paraibano. Utilizando-se recipientes estéreis retirou-se cerca de $300 \mathrm{~g}$ de amostra do solo entre 1-9 $\mathrm{cm}$ de profundidade. Posteriormente, foram realizadas diluições seriadas a partir de $10 \mathrm{~g}$ de cada amostra homogeneizada até $10^{-7}$ diluição em solução fisiológica estéril. Após $15 \mathrm{~min}$ de agitação em vortex, foram semeadas as três últimas diluições em alíquotas, $0,1 \mathrm{~mL}$ do sobrenadante em meio de cultivo KusterWillians. Posterior a incubação a $28^{\circ} \mathrm{C}$ por $5 \mathrm{~d}$, as colônias com características de Streptomyces foram isoladas, e identificadas por meio de microcultivo, testes fisiológicos e ensaios citoquímicos (Serrano \& Sandoval, 1992; GarciaQuintana, 1997).

\section{Preparação dos extratos a partir dos Streptomyces}

Após triagem antimicrobiana através do método de difusão em meio sólido com bloco de agar (Ichikawa et al., 1971), as cepas SP1 e SP3 apresentaram os melhores resultados entre todas e seguiram na realização dos testes frente às espécies fúngicas. As linhagens foram semeadas em placas de Petri contendo o meio ISP-2 e incubadas em estufa BOD a $30{ }^{\circ} \mathrm{C}$ por $5 \mathrm{~d}$. Após incubação, blocos de gelose $(6 \mathrm{~mm})$ foram transferidos para frascos de Erlenmeyer contendo $50 \mathrm{~mL}$ do meio ISP-2. Em seguida, iniciou-se incubação sob agitação $(180 \mathrm{rpm})$, a $28{ }^{\circ} \mathrm{C}$ por $48 \mathrm{~h}$. Posteriormente, $10 \%(\mathrm{v} / \mathrm{v})$ deste pré-inóculo para cada linhagem foi transferido para Fernbach, contendo cada $300 \mathrm{~mL}$ do meio ISP-2 e cultivados por $48 \mathrm{~h}$ sob as mesmas condições de temperatura e agitação. Após fermentação foram centrifugados a $3000 \mathrm{rpm}$ por $10 \mathrm{~min}$ para a separação do líquido fermentado da massa celular.

Para a extração dos princípios ativos de cada líquido fermentado foi utilizado como solvente o etanol. Utilizou-se uma proporção de 1:2 dos líquidos fermentados, seguido da agitação durante $20 \mathrm{~min}$ em shaker. Foi realizada a separação das fases, uma orgânica composta pelo solvente com o princípio ativo extraído, e outra aquosa que consistiu na fase aquosa do líquido esgotado. Em seguida, as fases com os princípios ativos foram concentradas em evaporador rotatório, e mantidas em dessecador.

\section{Microrganismos e meios}

As linhagens selecionadas para a realização dos testes de antagonismo pós-triagem antimicrobiana foram o Aspergilus niger LM 05, Aspergillus fumigatus ATCC 40640, Trichophyton rubrum ATCC 1683 e Trichophyton inkin LM 067. As espécies foram mantidas em meio Sabouraud dextrose (DIFCO) por $14 \mathrm{~d}$. a temperatura ambiente.

\section{Ensaios de atividade antimicrobiana}

Foram preparados inóculos em solução salina estéril a $0,89 \%$ das linhagens testes ajustadas na escala de Mc Farland (01 x $\left.10^{8} \mathrm{UFC} / \mathrm{mL}\right)$, mantidas a temperatura ambiente. A atividade inibitória foi verificada pelas técnicas de difusão com discos em meio sólido (Bauer et al., 1966) e microdiluição (Nccls, 2002). No ensaio de difusão com discos, foi adicionado em uma placa de Petri estéril $1 \mathrm{~mL}$ de cada microrganismo-teste, seguido de $20 \mathrm{~mL}$ do meio Sabouraud dextrose fundido a $45^{\circ} \mathrm{C}$. Após solidificação, foram embebidos discos de papel de filtro com $30 \mu \mathrm{L}$ de cada extrato em uma concentração de $10 \mathrm{mg} / \mathrm{mL}$ e colocados sobre a superfície do meio de cultura contendo os microrganismos testes. As placas foram mantidas a temperatura ambiente por $14 \mathrm{~d}$. Após incubação os halos foram medidos e comparados com a droga controle, cetoconazol $50 \mu \mathrm{g} / \mathrm{mL}$. A determinação da concentração inibitória mínima (CIM) dos extratos foi realizada através da microdiluição, em placas de ELISA com noventa e seis poços estéreis. Foram distribuídos 100 $\mu \mathrm{L}$ de caldo Sabouraud dextrose nos orifícios das placas, exceto na linha dez. Em seguida, foram dispensados 100 
$\mu \mathrm{L}$ de cada extrato em cada placa em uma concentração de $20 \mathrm{mg} / \mathrm{mL}$ nas cavidades da primeira linha. Seguindo o processo de diluição seriada, foram retirados $100 \mu \mathrm{L}$ da cavidade mais concentrada para a cavidade sucessora. Nos orifícios de cada coluna foram dispensados $10 \mu \mathrm{L}$ do inóculo correspondente a cada cepa ensaiada. A linha onze foi reservada para o controle negativo com o caldo e a linha doze para o controle positivo com a droga cetoconazol 50 $\mu \mathrm{g} / \mathrm{mL}$. Os ensaios foram realizados em triplicata para cada extrato, incubados a temperatura ambiente por até $14 \mathrm{~d}$. As leituras de determinação da CIM dos extratos Sp-1 e Sp-3, sobre as cepas testes, foram realizadas através do método visual, observando a formação ou não do aglomerado celular, considerando como CIM a menor concentração do produto em teste.

\section{Determinação da cinética de morte microbiana}

O estudo da interferência das concentrações inibitórias mínimas dos extratos $\mathrm{Sp}-1$ e $\mathrm{Sp}-3$ sobre a viabilidade das cepas fúngicas foi realizado através da avaliação do crescimento radial das colônias em milímetros dos fungos filamentosos em intervalos de $(0,2,4,6,8$, 10,12 e 14 d) em triplicata. Inicialmente, inoculou-se em placas de Petri estéreis $9 \mathrm{~mL}$ de meio Sabouraud acrescido de $1 \mathrm{~mL}$ de cada extrato em concentrações estabelecidas a partir do valor da CIM, homogeneizando até resfriamento. Em seguida, retiraram-se fragmentos de aproximadamente $2 \mathrm{~mm}$ de cada cepa fúngica ensaiada, colocando-os no centro da placa, incubando a temperatura ambiente por 14 d. No controle positivo foi utilizado $9 \mathrm{~mL}$ do meio $+1 \mathrm{~mL}$ de cetoconazol na concentração de $50 \mu \mathrm{g} / \mathrm{mL}$ e o controle negativo $9 \mathrm{~mL}$ do meio $+1 \mathrm{~mL}$ de salina estéril (Thyagara \& Hosono, 1996; Adam et al., 1998; Daferera et al., 2000; Rasooli \& Mirmostafa, 2002).

\section{Análise estatística}

Dados foram analisados estatisticamente utilizando ANOVA-Bonferroni, e considerados significativos com $\mathrm{p}<0,05$.

\section{RESULTADOS E DISCUSSÃO}

$\mathrm{Na}$ avaliação dos resultados da atividade antifúngica através do teste de difusão com discos em meio sólido o extrato $\mathrm{Sp}-1$ apresentou inibição fúngica com halos entre 21-31 mm frente às espécies testes. O extrato Sp-3 apresentou efeito antagônico com halos de inibição superior ao extrato $\mathrm{Sp}-1,24 \mathrm{~mm}$ contra o T. rubrum ATCC 1683 e $35 \mathrm{~mm}$ frente ao A. fumigatus ATCC 0406. Na Tabela 1 pode-se observar todos estes dados, bem como, os valores inibitórios da droga controle, inferior aos extratos testados, droga esta, comumente utilizada na terapia antifúngica. Os resultados apresentados pelo efeito dos extratos são relevantes e podem ser comparados com outras literaturas que apresentam estudos realizados com cepas nativas de Streptomyces spp., com atividade antifúngica, a partir de solos no Brasil (Schlingmann et al., 1999; Bachiega et al., 2005).

$\mathrm{Na}$ Tabela 2 observa-se os dados de inibição em concentrações diferenciadas dos extratos Sp-1 e $\mathrm{Sp}-3$ frente as amostras de fungos filamentosos. $\mathrm{Na}$ concentração inibitória mínima (CIM) de $0,078125 \mathrm{mg}$ os extratos $\mathrm{Sp}-3$ e Sp-1 apresentaram o mesmo resultado frente à cepa de $T$. inkin LM 067. Na concentração inibitória mínima (CIM) de $0,15625 \mathrm{mg}$ o extrato $\mathrm{Sp}-1$ mostrou-se eficaz em seu efeito antagônico contra o $A$. niger LM 05, T. inkin LM 067 e A. fumigatus ATCC 0406. O Sp-3 inibiu em mesma concentração as espécies $A$. niger LM 05, T. inkin LM 067 e T. rubrum ATCC 1683. Estes dados de inibição são corroborados por outras literaturas que também realizaram pesquisa de novos compostos antimicrobianos através de triagem clássica de produtos naturais (Groll et al., 1998; Ujikawa, 2003). $\mathrm{Na}$ microdiluição, o grupo controle sem droga inibitória apresentou o resultado esperado com crescimento para todas as espécies, e o controle com a droga antifúngica padrão cetoconazol $50 \mu \mathrm{g} / \mathrm{mL}$ inibiu o crescimento das cepas $T$. inkin LM 067 e A. fumigatus ATCC 0406.

No Gráfico 1 observam-se as curvas da cinética de morte para as duas espécies do gênero Aspergillus, destacando o relevante efeito antifúngico dos extratos Sp-1 e Sp-3. Na análise entre o controle e extratos todos os resultados foram significativos com redução do crescimento micelial dos fungos $(\mathrm{p}<0,05)$. Na análise controle e cetoconazol, a inibição da droga não foi significativa no ensaio com a cepa A. fumigatus ATCC 0406. No Gráfico 2 a inibição do crescimento micelial foi significativo para a cepa ensaiada T. inkin LM 067 com valores $(\mathrm{p}<0,01)$, na relação entre controle e extratos e controle e cetoconazol. Alguns trabalhos vêm explorando o potencial de substâncias bioativas extraídas de plantas e de microganismos contra o crescimento micelial de fungos patogênicos e outros microrganismos. Salvagnni et al. (2008), avaliou a atividade antibacteriana a partir de extratos de Myrtus communis L. frente a cepas Gram positivas e Gram negativas. Moreira (2006), determinou a cinética de algumas substâncias bioativas contra fungos dematiáceos, C. cladosporiodes e F. compacta, observando efeito positivo contra o crescimento radial ao longo de 14 d de exposição. Sharma \& Tripatti (2006), observaram que o óleo de Citrus sinensis na concentração de $3,5 \mu \mathrm{g} / \mathrm{mL}$ foi capaz de inibir $100 \%$ do crescimento micelial do A. niger após 7 d de exposição. Pode-se inferir que os extratos obtidos a partir das cepas nativas de Streptomyces spp de solos paraibanos apresentam-se notáveis quanto à produção de metabólitos bioativos capazes de inibir o crescimento de cepas fúngicas patogênicas, apresentando-se como uma nova rota na busca por novas drogas antimicrobianas. 
Tabela 1. Atividade antifúngica dos extratos Sp-1 e Sp-3 isolados de Streptomyces spp contra fungos filamentosos.

\begin{tabular}{lccc}
\hline \multirow{2}{*}{ Espécies fúngicas } & \multicolumn{3}{c}{ Método de difusão com discos em meio sólido (halos em mm) } \\
\cline { 2 - 4 } & Extrato Sp-1 & Extrato Sp-3 & Cetoconazol $(50 \mu \mathrm{g} / \mathrm{mL})$ \\
\hline A. niger LM 05 & 24 & 29 & 20 \\
T. inkin LM 067 & 25 & 31 & 19 \\
A. fumigatus ATCC 0406 & 31 & 35 & 21 \\
T. rubrum ATCC 1683 & 21 & 24 & 20 \\
\hline
\end{tabular}

ATCC: America Type Culture Collection, LM: Laboratório de Micologia

Tabela 2. Ensaio antifúngico em placas de microdiluição dos extratos $\mathrm{Sp}-1$ e $\mathrm{Sp}-3$ isolados de Streptomyces spp contra fungos filamentosos.

\begin{tabular}{|c|c|c|c|c|c|c|c|c|}
\hline $\begin{array}{c}\text { Fungos } \\
\text { Filamentosos }\end{array}$ & $\begin{array}{c}\text { Aspergillus } \\
\text { niger } \\
\text { LM } \\
05\end{array}$ & $\begin{array}{c}\text { Aspergillus } \\
\text { niger } \\
\text { LM } \\
05\end{array}$ & $\begin{array}{c}\text { Trichophyton } \\
\text { inkin } \\
\text { LM } \\
067\end{array}$ & $\begin{array}{c}\text { Trichophyton } \\
\text { inkin } \\
\text { LM } \\
067\end{array}$ & $\begin{array}{c}\text { Aspergillus } \\
\text { fumigatus } \\
\text { ATCC } \\
0406\end{array}$ & $\begin{array}{c}\text { Aspergillus } \\
\text { fumigatus } \\
\text { ATCC } \\
0406\end{array}$ & $\begin{array}{c}\text { Trichophyton } \\
\text { rubrum ATCC } \\
1683\end{array}$ & $\begin{array}{c}\text { Trichophyton } \\
\text { rubrum ATCC } \\
1683\end{array}$ \\
\hline $\begin{array}{l}\text { Extratos } \\
\text { (conc. em mg) }\end{array}$ & Sp-1 & Sp-3 & Sp-1 & Sp-3 & Sp-1 & Sp-3 & Sp-1 & Sp-3 \\
\hline 10,0 & - & - & - & - & - & - & - & - \\
\hline 5,0 & - & - & - & - & - & - & - & - \\
\hline 2,5 & - & - & - & - & - & - & - & - \\
\hline 1,25 & - & - & - & - & - & - & - & - \\
\hline 0,625 & - & - & - & - & - & - & + & - \\
\hline 0,31250 & - & - & - & - & - & + & + & - \\
\hline 0,15625 & - & - & - & - & - & + & + & - \\
\hline 0,078125 & + & + & - & - & + & + & + & + \\
\hline Controle* & + & + & + & + & + & + & + & + \\
\hline $\begin{array}{l}\text { Controle+ } \\
\text { Antifúngico** }\end{array}$ & + & + & - & - & - & - & + & + \\
\hline
\end{tabular}

**Padrão cetoconazol $50 \mu \mathrm{g} / \mathrm{mL}$; *Caldo Sabouraud + microrganismo; Sp-1 e Sp-3: Extratos secos etanólicos; ATCC: America Type Culture Collection; LM: Laboratório de Micologia; (-) Ausência de crescimento microbiano; (+) Crescimento microbiano

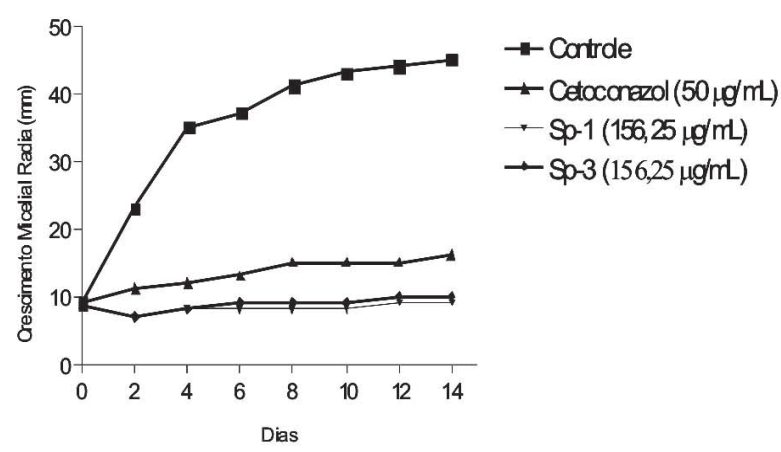

Aspergillus niger LM 05

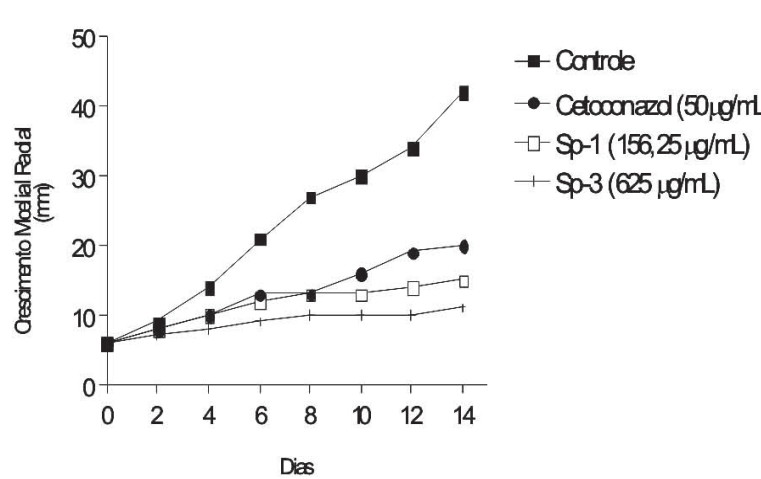

Aspergillus fumigatus ATCC 0406

Figura 1. Efeito dos extratos Sp-1 e Sp-3 isolados de Streptomyces e da droga cetoconazol sobre a cinética de morte microbiana de A. niger LM 05 e A. fumigatus ATCC 0406. ANOVA-Bonferronis $(\mathrm{p}<0,05)$. 

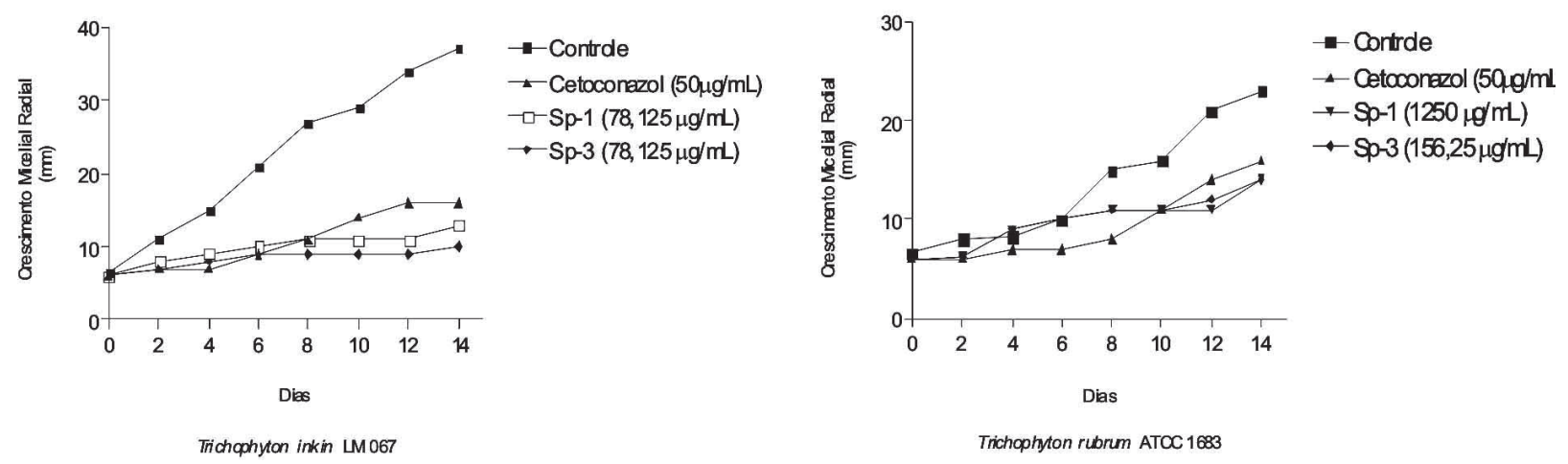

Figura 2. Efeito dos extratos Sp-1 e Sp-3 isolados de Streptomyces e da droga Cetoconazol sobre a cinética de morte microbiana de T. inki LM 067 e T. rubrum ATCC 1683. ANOVA - Bonferronis com ( $<$ 0,01), para o T. inkin LM 067.

\section{REFERÊNCIAS}

Adam K, Sivropoulou A, Kokkni S, Lnaras T, Arsenakis M 1998. Antifungal activities of Origanum vulgare subsp. Hirtum, Mentha spicata, Lavadula augustifolia and Salia fruticosa essential oils against human pathogenic fungi. J Agr Food Chem 46: 1739-1745.

Bachiega GL, Vilegas W, Ujikawa K 2005. Antibiótico antifúngico produzido por um estreptomiceto da região de Araraquara. Rev Cienc Farm Basica Apl 26: 29-37.

Bauer AW, Kirby MDK, Sheries JC, Truck M 1966. Antibiotic susceptibility testing by a standardized single disk method. Am J Clin Pathol 45: 493-496.

Daferera DJ, Ziogas BN, Polissiou MG 2000. GC-MS analysis of essential oils from some Greeks aromatic plants and their fungitoxicity on Penicillium digitatum. J Agr Food Chem 48: 2576-2581.

Garcia-Quitana H, Zaror CL, Leiva P.S 1997. Efecto antibiótico de cepas silvestres de Streptomyces aisladas de suelos chilenos. Rev Med Chile 125: 1157-1164.

Groll AH, Delucca AJ, Walsh TJ 1998. Emerging targets for the development of novel antifungal therapeutics. Trends Microbiol 6: 117-124.

Ichikawa T, Ishikura T, Osaki A 1971. Improvement of kasugamycin-Producing strain by the agar piece method and theprototroph method. Folia Microbiol 16: 218-224.

Li H, Qing C, Zhang Y, Zhao Z 2005. Screening for endophytic fungi with antitumour and antifungal activities from Chinese medicinal plants. World J Microb Biot 21: 15151519.

Lima OG, Viana SP, Carvalho JP, 1975. Menadione and its stimulant effect on the growth of animals. Rev Inst Antibiot 14: 29-38.

Moreira ACP 2006. Avaliação da atividade antifúngica de óleos essenciais e fitoconstituintes sobre fungos dematiáceos. Paraíba, 94p. Dissertação de Mestrado, Programa de Pós Graduação em Produtos Naturais, Universidade Federal da Paraíba.

NCCLS 2002. Reference method for broth dilution antifungal susceptibility testing of yeast. Nccls 17: Document m
27-A2.

Rasooli I, Mirmosfata SA 2002. Antibacterial properties of Thymus pubecens and Thymus serpyllum essential oil. Fitoterapia 73: 244-250.

Salvagnni LE, Oliveira JRS, Santos LE, Pietro RCLR 2008. Avaliação da atividade antibacteriana de folhas de Myrtus communis L (Myrtaceae). Rev Bras Farmacogn 18: 241-244.

Sanches-Marroquin A 1958. Streptomyces de amplio espectro antimicrobiano aislados de suelos de Brasil. Rev Inst Antibiot 1: 53-63.

Serrano JA, Sandoval H 1992. Tecnnicas para el isolamiento $y$ diagnóstio de los Actinomycetales, Manual de Laboratorio. Valdivia: Facultad de Medicina UAL.

Scharma N, Tripahi A 2006. Effects of Citrus (L) Osbeck epicarp essencial oil on growth and morphogenesis of Aspergillus niger. Can J Microbiol 47: 9-17.

Schlingmann G, Milne L, Bordes DB, Carter GT 1999. Strevertenes, antifungal penteene macrolides produced by Streptoverticillium LL-30F848. Tetrahedron 55: 5977-5990.

Strobel GA, Daisy B 2003. Bioprospecting for Microbial Endophytes and Their Natural Products. Microbiol Mol Biol R 67: 491-502.

Thyagara N, Hosono A 1996. Effect of spice extract on fungal inhibition. Lebensm wiss technol 29: 286-288.

Tresoldi AT, Barison EM, Pereira RM, Padoveze MC, Trabasso P 2000. Risk factors associated with the acquisition of multiresistant bacteria in a pedriatic nursery. $J$ Pediatr 4: $275-286$

Ujikawa K 2003. Antibióticos antifúngicos produzidos por actinomicetos do Brasil e sua determinação preliminar nos meios experimentais. Braz J Pharm Sci 39: 149158.

Wiyakrutta S, Riubolmas N, Panphut W, Thongon N, Danwisetkanjana K, Ruangrungsi N, Meevootisom V 2004. Endophytic fungi with anti-microbial, anti-cancer and anti-malarial activities isolated from the medicinal plants. World J Microb Biot 20: 265-272. 